\title{
Current Landscape of Mental Health in Children and Adolescents in Northeastern, Brazil
}

\begin{abstract}
Andrea Sampaio de Matos ${ }^{1}$, Hyanne de Abreu Cândido de Souza ${ }^{1}$, Walkiria Régia Ferreira Sousa de Sá1, Carlos César Messias Silva1, Jucier Gonçalves Júnior ${ }^{1}$, Erich Pires Lisboa', Modesto Leite Rolim Neto ${ }^{1}$
\end{abstract}

\section{Abstract}

The narratives foment themselves by a discourse rooted in the words of indecision, doubt, insecurity, powers and perils, pessimism and, above all, by the uncontrollable desire of escaping from the pain of being that bother them. The Family members constantly warn the listener or interpreter of the internal dissatisfaction that alert their children. To interpret and listen to the rhetoric of enchantment of the family is one of the effective means to treat and prevent the disease. In this case, the listening must be unreservedly committed, because it transcends the family boundaries, passing to need support and unconditional zeal of the clinical apparatus.

\section{Introduction}

Foucault [1], in his last course at Collège de France, from February to March 1984, under the title "Lé courage de la verité" (The Courage of truth), after study Platão's work about Socrates' death, it was demonstrated how the practice of truth telling (parrhesia) and the "the care of the self" can conduce us to our own truth. And, in this sense he claimed to Dreyfus and Rabinow [2]: "What strikes me is the fact that in our society, art has become something which is related only to objects and not to individuals, or to life". The life of every individual could not be a work of art?" And it is here that it will translate the truth beyond the limits of discourse to operate in the field of rhetoric, of allegories, of dialects, and of enchantment. Clearly, the record of these facts, by their limited and sometimes unavailable nature, translates a diversified thinking in the form of analyzing the will to truth, sought by the family members, especially by inquietude and by anxiety of a truth that comfort them.

1 Faculty of Medicine, Federal University of Cariri, UFCA, Barbalha, Ceará, Brazil.

\section{Contact information:}

Modesto Leite Rolim Neto.

Đ modestorolim@yahoo.com.br

Keywords

Family Narratives; Children; Depression; Psychic Suffering. 
The biggest truth was not in what the discourse was or in what the discourse, said: it has come, however, the day when the truth moved from the ritualized act of enunciation, effective and fair, to its own enunciation: for its meaning, for its form, for its object, for its relation to the preference. [3]

And this enunciation is, exactly, the expression of its own subjective disorganization. The adverse situations are highlighted by saying the will to truth.

In the family members' view, this will of truth becomes the desire of determine if the depressive condition is authentic or not.

What is called depression today - if we exclude the melancholic psychosis - it is eminently the status of the soul that hides the subject more than revels it; a kind of ethic retreat that impede the subject - by comprehensible reasons, sure - of assuming the consequences, better saying, of the existence of unconscious, whose irruption could summarize itself with the following discovery: "I do not want what I desire". [4]

By saying "my child is sick of the nerves" or "suffer from nerves", the family members find themselves in distress, because of that they are subjects of a belonging, consequently they transcribe the pain of the soul into passwords that give access to their universe, the need for special attention to such particularity, bringing to light the packed words that follow the itinerary of pain and psychic suffering in what appropriates the thematas reconstruction process [5] and the hyponemathas [6]. Thought the (re) telling the lived, revealing the secrets of Pandora's box, they meet moments in which the discourses come out, in words that if they wish to leave flow are opened, where what is hidden in the chance establish voices and words, hopping that one of them "speak speak" [7], from what remain of them, that is the reminiscent truth.

In this sense, the family members have an anagram of their depressive children; a creature that doesn't know anymore with whom it must live and share its daily routine. [8] I would not like to be forced to enter in that uncertain order of discourse; I would not like to see with him what is peremptory and decisive; I would like to have him close to me as a calm , deep, and indefinitely open transparency, and that the others could answer my expectation, and that the truths, one at a time, rise themselves; It could be necessary only take me, in it and for it, as a happy rudderless boat. [3]

In that perspective, the will to truth by the families hang in the field of their narrative, in order to measure values, questioning ideas, abolish ideals and, above all, look for comfort. Those narratives show themselves modern, in order to translate an extensive cultural text [9], enabling an understanding of lived context as social mechanics to the social semantics. [10] According to Foucault's countersignature, There is the possibility of this discourse flee from a right order, determined to take on, effectively, the end of the intended truth.

When the universal path is not for happiness, the access to it is entirely singular. The uniqueness of this path requires us to consider that the conditions of its possibility are unequal, or unevenly distributed. There is no way preformed neither in the microcosm, nor in the macrocosm to prepare the subject to get it. [4]

In the field of childhood depression treatment, the narrative fulfills its facilitator role, by expressing the will to truth of the family members. Thus all its rhetoric gives a valuable subsidy on diagnosis and treatment of disease, notably by bear with specific traits in the act of exposing dangerous thoughts orally [11], and then filter their real desire that is stereotyped in its truth: "cure", welcome, inner peace, happiness, serenity and joy. These predicates appear to pass us the tangible meanings, from the words spoken by the depression, on hold. So there would be no start; and instead to be the one where the discourse comes out, it would be before the chance of its course, a small gap, the point of its possible disappearance. [3] 
To think of a black time passed is a terrible evil. Depression can easily be the consequence so in the excess of which was cheerful as in the excess of which was horrible. The worst of the depression lies in a present moment that cannot escape the past that idealizes or regrets. [11]

It is the manner that must be thought to the detriment of treatment given to the family, in which we can consider fundamental to ask about "how" this manifests itself and about "what" it is searched to translate face to the suffering. What is found is a persistent, opaque, lasting, and intense complaint, of a feeling of depressive origin for which it takes time. [4]

In that same treatment, to listen to this truth is a stabilization condition of depression, especiaIly when it is known that the family is lacking in ears and riddled with words to be said and unsaid through the oral narratives. Essentially, in this topic, it emanates the real objective of to rescue the narrative in the body of the discourse, including this same discourse as a source of invaluable unpublished information and/or reissued.

Besides, to follow the process and to participate of it, it must be considered that in the condition of sharing the family members attitudes front of the contents of their enunciation, what is in question is the production of new forms of subjectivities of what they complain, that is neither simple nor automatic. It Implies changes in position of the subject, in fantasy and in creating conditions to make front to the repressed, which means opening the censored chapter of its life, and this is not without anguish. [4]

Hence the need to reference the expression of the speaker's attitude with respect to the content of its statement. [12] The will to truth of the family members, however, it is related to how to say or unsay the word though the voices restitution systems, sheltered in said words, and words waiting be said. We cannot deprive the family of the psychic ability of rediscover, speaking, and the resource of temporal rhythmic modulations. The children's families ask for time. [13]

The childhood depression narrative is ruled in a discursive order, where voices are decisive factors in the achievement of their family members' translation. It looks for reaffirm the said in its rhetoric, it ways fears the disease as something in untamable, producing a large desperate disposition. The family members, although, reference, in their words, the potential of the internal strength that motivates their children to crop the moments of its life, by saying, they claim for liberation of that sense.

The childhood depression is a way to interrupt especially the innocence: the mental suffering that conduces it, it get used to be prolonged, intense, intimate and indivisible, by letting the family members, friends and colleague to handle with a kind of loss almost unfathomable, such as the feeling of guilt. The depression brings in some family members as consequence a level of confusion and devastation that, in its largest part, it stays beyond any description. [14]

The Family members constantly warn the listener or interpreter of the internal dissatisfaction that alert their children. After tireless alerts, they are to be taken as fact; those voices perceived only by it and then establish a consolidated ideation of disease of the nerves. However, the narratives foment themselves by a discourse rooted in the words of indecision, doubt, insecurity, powers and perils, pessimism and, above all, by the uncontrollable desire of escaping from the pain of being that bother them.

To listen to, committed, the potential of family members narratives is to lessen the risk of the execution of the pain and the psychic suffering, especially when it is still in the stage of saying and unsaying. To interpret and listen to the rhetoric of enchantment of the family is one of the effective means to treat and prevent the disease. In this case, the listening must be unreservedly committed, be- 
cause it transcends the family boundaries, passing to need support and unconditional zeal of the clinical apparatus.

We believe that the words are strong; they can crush what we fear when the fear seems more terrible than the positive side of life. We turn, with increasing attention to the love. The love is another way to advance. They need to act together: when alone, the pills are a weak poison, the love a blind knife, an insight, a rope that crack under the excess of effort. With them together, if you are lucky, you can save the climbing tree. [11]

In terms of depression, the word heard with ethics and commitment, combined with the medication and its monitoring can be a powerful icon in the treatment of disease. We have seen, through our studies, which the deficiency of a "committed listener" corroborates tended to the shimmer of chronicity to childhood depression phenomenon, so it is, effectively, with listening and welcome to achieve its possible inhibition.

Thus, in childhood, the pain and psychic suffering are taken as a symptom, and not as a cause of child depression. This symptom is expressed in the will of the family members to set free "their children" from the depression, by punishing severally their hyperactivity, in order to put an end to internal conflicts caused, in degree of despair.

Through the psychoanalysis, the childhood depression is configured as a moment when the child "it is out of mind" and, because of that, it can attack itself. It is the lowering of the ego self-defense capacity, which allows the irruption of disease. With the gradual loss of libido, the anxiety assumes the personality preventing the ego acts and, with that, the child presents specific content of sadness, low self-esteem, loneliness and need to call people's attention that surround It. [15]

In the same way that, for psychoanalysis, child depression in lato sensu occurs in a long and lasting moment of fragility of self-defense mechanisms of psyche, the body becomes an instrument easy to depreciation, and so it is handled as revenge itself. Being depressed is a State that spends a lot of fragility. This fragility is expressed on the vulnerability of thought, in desperation, in pain.

The pain and psychic suffering generated by the childhood depression depend on each family to set limits to their tortures outlined in living with the disease. Fortunately, the boundaries that most families establish for themselves are high. Nietzsche once said that the idea of limits imposed by the man maintains it most of the time in the darkest part of the night. We believe that the more completely one reconciles with the idea of rational displeasure, safer will be of pain and irrational.

Freud, in a letter addressed to Abraham, claims that "depression is the persistence of unconscious investment in the object-representation". [16] There are evidences that the problems connected to family structure and support are related to childhood psychiatric disorders, specifically to mood disorders. [17] it is important to highlight that the approach of childhood depression, it is necessary to consider the direct clinical observation, by complementing continually the data analysis of clinical evolution, including the signs and symptoms, bringing to the families a contact with diagnosis related to conduction, management, and treatment, involving not only the physical well-being, but also the emotional and social. [18]

As a rule, the diagnosis occurs from the presence of certain symptoms that manifest themselves in a certain length, frequency, and intensity of time which the world recognized psychiatric manuals that are in use that describe thoroughly to designate what is commonly called "depression" or "depressive diseases". [19]

It is worth noting, however, that diagnose child depression is not the same task that diagnose any disease, because of its peculiar character of pain and/or psychic suffering that changes the specificity of representation of the disease [20], as well as the mechanisms of translation to clinical and therapeu- 
tic logic. It is necessary to stamp, again, that the listening must be sensitive and committed.

We live a scattering of vanishing lines and streams of deterritorialization effects and speed favor the production of subjective mutations open to experience - of the space, of the time, of the body, of the other - and others opened to a tight identifiable subjectivity. [4]

We are at a time conducive to suffer, because of the profusion of therapies, medicines etc. [87] In addition, and perhaps as a result of the deterritorialization flows that pervade society today in all its dimensions, is a "great" time for that suffering find difficulties to be subject and, from there, treated. Now, it is referred to a particularity of vital operating and delegate to expert. [4]

In terms of treatment, the medication is the element commonly used by most professionals in the field, notably by having a secure and fast stabilization effect of depression. Pharmacological manipulation predominates in the treatment of the causes and in the prophylaxis of the act. In casu, we want to valorize the listening as a way to treat and prevent depression, mainly because the depressed is extremely lacking in listening and it does not require a degree of impact on the mitigation of the pain of being. There is no need to separate the use of medication and the psychotherapy. They must act together to achieve the end sought.

Antidepressant drugs, which act more specifically on individual neurotransmitters, not only change the clinical practice radically by its popularity and dissemination, but also provided additional evidence for the role of neurotransmitters in the origins or the perpetuation of child depression. Classified as selective serotonin uptake inhibitors, they act mainly by blocking the removal of serotonin in the synapses. This, in turn, increases the availability of serotonin in the brain. [14]

At this point, specifically, the Pharmacology and the narrative appear in the treatment and prophylaxis of depression symptoms. However, when no one listens, the hopes and the troubles experienced by the patient centralize on medication, thus creating a dependency relationship.

\section{Method}

The search for (re)editing the family narratives through the registers that marked the path of their children in the levels of pain and psychic suffering, causing them what is named childhood depression and its consequences, opens access to dynamics of words that seem important in the process of decoding of concepts, metaphors, passwords, practices, and effects in the voices that need interpretation. It captures a complex network of configurations that the narrative, in terms of analysis field, it would help us to go through the said and unsaid words.

By understanding the concept of field as a signal that reminds us what must be done, known and verified [21], we would be providing the flexibility analysis. [22] In these terms, the narrative seeks to trace the (re) contextualization of childhood depression field, in what is proper and essential, to be translated in the voices that seek meaning in their concerns, in its helplessness.

We would be creating, by this way, narratives with a social research aim [23], reconstructing the events, from the perspective of the informant, as directly as possible. In a search for the what [24], and for the how [24] involved in recasting of what causes, by speaking, a way for translating the lived situation. It is essential, in the process, not to lose sight of how the family members speak of their lives, the language used and the connections with their depressed children. [25]

To approach the narratives research method, assumes understand them not only as a listing of events, but as an attempt to turn them on, in the time and in the sense. [23] Thought on this way, the narrative constituted through plots providing the context for the understanding of the lived. The 
narrative is present in every place, in every society it is simply there, as life itself. [26]

Discussing the authenticity of the particular perspectives of family members, we draw attention to the fact that the narrations are rich of indexed affirmations. [23] It is from this option that will appear the primary interest for what refers to the experience of lived, in the course of events and actions that, in profusion, make us understand the process of pain and psychic suffering, interconnected to the directions established by the passwords, expressed in the plot of the depression. We are therefore seeking to show the place, the time, and the guidelines of the symbolic system of the actors. [27]

\section{The sample universe}

The universe of the study comprised 24 family members, with ages ranging from 45 to 70 years, which sought the services of the Center (CAPSi) in a small town of the Northeast. The consultations were motivated by circumstances involving psychic suffering or psychic pain, through the handling of passwords that included in the narrative the use of said and unsaid words in the form of concepts like depression, disease of the nerves.

At first, it was performed through registers, a survey of family members, from the notifications of cases in the transit of medical and psychological consultations. With that information, we started to map our sample, considering:

1. Family members (parents or guardians) identified in the registration of the Center (CAPSi), considering the diagnosis of childhood depression of their children;

2. Family members that had children with a diagnosis of childhood depression, according to the criteria of ICD-10;

3. Family members who have agreed to participate in the survey;

4. Participants must sign their informed consent document.

\section{Procedures}

We are analyzing the narratives in the said and unsaid discourse of family members, through six steps $[28,29]$ :

1. Detailed transcript of the verbal expressions of respondents;

2. Division of the text into indexed and nonindexed material. The indexed propositions having as concrete reference "who did what, when, where and why", while the unindexed propositions take into account the events, values, judgments, and all forms of a widespread "knowledge of life";

3. The use of text indexed content, to analyze the development of the events of each person in their trajectories;

4. The investigation of unindexed text dimensions as "analysis of knowledge";

5. The understanding of group and comparison between individual trajectories;

6. Comparison of cases and individual trajectories within the context and establishment of similarities. This process has allowed us to identify the collective trajectories.

Pursuing this direction, we are, through the thematic analysis, mapping the construction of decoding of frames that subsidized the narrative, revisiting the idea of reducing the text units in two rounds of paraphrases. [23] The first round is related to the paragraphs that were paraphrased into synthetic sentences. The second step gives to the sentences new paraphrases, in order to make it possible to find keywords. In this way, the text was placed in three columns: cultural, psychological and biological aspects.

Thought that ratiocination, we are developing a category system that focus on the place marked by construction of senses, in what circulates the movement of voices, inside the significant that needs interpretation. The final product will be in an interpretation of interviews, by gathering relevant structures of the informants with the interviewer. [23] 
This process takes us on a particular relationship with the social cartography, helping us to go beyond sterile dichotomies and arbitrary opposition. [30] The cartography would be one way of thinking about established things to its own materiality, and to its self-organization forms in which generate resistance and perverse effects, neutralization and locks, autonomy and creativity. [31] Cartography came to contemplate the search for representing the narrative graphically and theoretically. [32, 33]

Chart assumes, therefore, in the analysis of the interviews, a double reading of the narratives, through what is called paradigmatic and sub paradigmatic reading. [34] In this work, the paradigmatic reading has been understood as a means of emphasizing the complexities in belonging and in coping with depression, as well as the suicidal ideations; and, in sub paradigmatic, it was sought its interpretation forms, linking actors, actions and deeds in time, to compare, formally, private courses and actions. [23]

\section{Results}

Family narratives contain regional dialects, metaphors, onomatopoeia, allegories that denote an eventual understanding that the discourse are texts in search of a context that explain them, that is, explained by them, forming a kind of complementarity between the enunciative and the real, first to their narrators, and after to their interpreters. [35]

The transcribed narratives make us perceive lived factual features, or a culture in the social practice of each one of them. Let's see what it teaches us about childhood depression a 57-year-old mother listened by us: "It is anguish, it is cold, and it is battle [...] one bad thing that's killing our son. It starts slow, then increases, taking life away. It is a weird thing that you don't have time to get there. It seems fire in time of wildfire".

The narrator makes a metaphorical parameter between acts of her everyday life, assigned to agri- culture, relating it to the depressive phenomenon that is affecting her son. Her discourse is linear, although melancholic. The mother recognizes the disease as something cyclical, that comes and goes, "Burns and extinguish", but that never comes to an end, which she anxiously search.

We noted that the mother in her discourse, says that what she feels and wants to feel, she recognize her child depression and learn how the disease changes but cannot dominated it. This is the search of truth by Foucault $[36,37]$, associated to the rhetoric of enchantment diffused by Lima. [35]

Other deposition expresses the conflicting relation between the parent and the time: "Life is slow and everything passes slowly". Nothing calls the attention. Only the room pays for my daughter, only the bed saves. I have no plan, so why to dream? I live the time of that past. Nobody understands my daughter. Neither do I understand what she feels. The understanding is complicated. It is loneliness, fear, and anguish of she died".

The childhood depressive phenomenon generates an excessive unpleasantness and inconvenience with the time, in order to bring the family members to past situations and to question a diversity of facts and episodes, after exhaustive attempts and after a long time, in order to translate the child between what was and what is now. Finally, there is an incessant search for a truth, and an answer of what is considered to be inexplicable about their pain. In that lineage, the family member in this lineage, the familiar lends his story through an own peculiar enunciation on living with the disease, for him, is able to guide the bewildered. Thus, the performer is the person to whom it is directed that enunciation, to be translated to a symbolism which gives knowledge about such condition.

A 68-year-old aunt speak: "This disease is like a passion fruit, everything ages, creating wrinkles in the heart and in the emotion. What saves is faith, but here comes the confusion, agitation, anxiety, and frustrations". 
Another 42-year-olf family member who works as blacksmith, reveals: "The depression of my son is like caustic soda, corrodes everything inside him".

Thus, the discourse said denotes the idea created around the childhood depression, giving it a character of uncertainty and doubt. These feelings cause fear and inconceivability in the life of family members.

The terms used by the family members, although, denotes cultural institutions introduced in its daily routine. When they speak "It is as a passion fruit", "It is as soda caustic", by trying to the annoyed situation caused by depression, we have the association between the regional dialects and allegories of the discourse. At the moment, we find the bag of words, which are understood as mythopraxis, while it merges the story of the disease in many symbols - allegories and metaphors - through them the story acquires meaning for those who participate and offer to the investigator, the signs to do the interpretative exercise. [38]

As we see, Foucault $[37,39,40]$ is punctual in focus the said and the unsaid as subsidiary sources of human nature. Similarly, in the field of the fiction, of the mythical and, consequently, of the poetics of social life, Lima [35] lend us his theory for us to identify that the family member word is not summarized in the simple and only act of saying and understanding, but also in the fact of us understand that it has a particular social meaning, front of what is felt by the child, intimately, in the depression. Hence the immersion of passwords that carry in their interior the pre-established knowledge in the improvement of skills to identify, describe the diagnostic passed to the child.

On this direction, the family members who give us their discourse show how the rhetoric of the disease and its regional culture, connected to their personal skills to tell and (re)tell the stories, are capable of determining, scientifically, the forms of interpretation of depressive phenomenon. Let's see how a 59-year-old mother, translates this posture: "The depression of my son is like a withe- red flower, it does not grew, and it is only a dry branch asking for water, the silence is our largest interpret".

From the depositions, it is possible the clipping of concepts, expectations, and prospects from the cure of depression. These questions are answered along the discourse, while speak develops naturally. However, the answers are camouflaged by the particular way of how each person says the things, which at the end, merges in common terminology to the class and the social condition in which they are inserted.

In the merge of this information, we identified a memory, a collective consensus about the depression, opportunity in which it was possible to ascertain how people can apprehend the depression as "disease of the nerves", without, however, to have a safer notion of what it will effectively be. This factor is associated to the precariousness of care at primary health center, because the doctors are tied to prescriptive injunctions of psychotropic substances and they exclude, most of time, the listening of what is brought in the meaningful story by the patient through its speak, in its enunciation process.

On this direction, it is also possible to take from the family narratives peculiar aspects of its cognitive position about the medical behavior in the relationship with them, mainly at the expense of the medication prescribed.

It is also noticeable, the way how the family members see the depression, among themselves and in the face of its social context. The way they conceptualize the disease, always giving it a different name of what effectively has, it is a particular trait. They call it "disease of the nerves" because it was on that way that they learned to reference the depression with the medical team available there. However, when they meet others in the corridors of the health center, by contacting themselves, they discover that they have children with depression, by the speaking of others who has experienced diagnostics, in different places of their habitat. The earliest forms of presentation in conceptual processes 
consist of childhood depression. The symbols revered by participants in the conceptualization of the realities of the depression, is a determining factor in the translation of mythopraxis that occur in the merger between social practice and the mythical, originating prose and poetry in the narratives emanated from them.

Based on the questions raised by the family members, in the face of the depression, the diagnosis shall exercise a broader role than the commonly established. While the doctor says that the patient has something and then prescribes, in most cases without adding any other information about the clinical situation and mental depression, raises the familiar uncertainties. In this way, the family member passes to create expectations because of that diagnosis, and then transforms it as its cultural molds.

The diagnosis, in this manner, shall be substantiated by "hear/say", through the merger of experiences with other doctors and/or with other localities, on the part of some patients. The moment when the family member finds through its pairs make possible to create defense mechanisms against the disease, from its conceptions and collective and cultural characteristics. These mechanisms, however, are not of clinical slant, but social.

It is established between the doctor and the family an interpersonal binomial. Let's see: the doctor makes the diagnosis to prescribe psychotropic and provide the "blue prescription" - legal condition to purchase the medicine. The family member leaves the doctor's office with a load of questions a lot bigger than the one that accompanies the daily life, the fact of its child be depressed. In the hallways of the service units, at the exit and entry of each of them, it is already established a communicative link, through which they await an innovation, a "cure". At this point, it is locked in a dialogue in which the discourses find themselves in the sound of voices that are interpreted.

\section{Conclusion}

The depression, in the optics of the family members listened, is synonymous with "disease of the nerves", "nervousness", and "suffering from the nerves". However, the terminology used to see the depressive phenomenon highlights the assertive that the conventional wisdom emanated the unsaid in the discourse said in the body of the oral narratives coming from it.

In that sense, the social and psychological phenomenon of childhood depression conquered its space on the trajectory of the family members' life as something abrupt, overpowering, ferocious and destructive, while aroused the excessive desire to extract a consistent response actually originated from a clinical knowledge, by an early diagnosis, as well as potential benefits of an intervention also early.

As a social phenomenon, the childhood depression comes as an event based on the idea of "cure", in the proximity of the family member's imaginary when producing the semiology of the disease by networks of ideas that cross in a diagonal motion. That crossing, by its contestable nature, brings up the question, from the collision of information from the clinical knowledge and from the popular knowledge.

The behavior of pain may be non-verbal, and it can also be standardized culturally. In his studies about body gestures, Le Barre [41] pointed out that the gestures differ in various cultures, so they can only be interpreted considering the context in which they appear. [42]

Next to the conquest of new worlds, new techniques, new knowledge and production of new materials, there is also the apology of the new and it eliminates the downgrading of millenary knowledge of tradition. Replace is the verb that we conjugate instead of to renew, to update, and to amplify. Beside the laborious creative imagination of scientists, there is also the gestation of a power complete and intra-scientific that transforms seeds of life into tools of death. [43]Notably, what we search to renew, to 
update and to amplify the humanizing tone in the relationship doctor-child-family.

In terms of suggestions for intervention and treatment of depression in the field of practical disposition, the proposal to be performed consists of a systematic sequence of actions which understand the structural form to revise and to rethink the way of approaching the phenomenon and, specially, the person who is incorporated by it, that is, to see the depressive child.

In relation to the qualification of health professionals focusing on the problematic of exclusion, of pain and of the psychic suffering, it is imperious, especially, the need to prepare the professional to treat and to prevent correctly the depressive child, mainly because of their condition of estrangement of family with the disease to conduce and to amalgamate the pain of being, which reflect itself in the continuous exercise of saying, of thinking and of living the disease with something anomalous and, at the same time, enigmatic to its rhetoric.

Through the information collected in our research, we observed that the crucial preparatory qualification to refine the multiple actions and/or procedures in correctly recognize the symptoms and signs, assigning significance to the words of the family members, who lack a counterpart.

Then, through this same narrative disposition, the approach of the depressive phenomenon an indicator of suicidal process - ideation, attempt and achievement - it emerges as an alternative of being seen the viability of intervention that diverge in the listening field as a factor to supply the gaps emanated of the speak, especially to establish a direction to children and partners of this relationship, in order to bolster the pain and the psychic suffering that lead to the suicide.

Thus, the relationship between the professional interpreter and the family member establish from a movement of action and reaction of the reality of the disease in the life context of the depressive child. This exchange of clinical and popularized values should be built simultaneously to the exchange of meaning and contact with the pathology and the human point of view.

Fears, insecurities, and uncertainties reflect, of all sorts, the intrinsic relationship between the subjects who knows the phenomenon and try to understand, to investigate. The hope and the longing for better quality of interpersonal and social relations, the desire for a more competent and humane future still depends on the way we deal with the knowledge and the way we develop our coexistence. It is possible that good fears match good intuitions. [44]

Parallel, it should be established a cartographical structure of information from the narratives in the fields of mental health, in the sense of shimmer a future perspective of supplying the flaws continually. Thus, that substantial reference of information in a desire for narratives of depression should subsidize the recognizable of the families of the depressive child, who says and unsays that the disease according to their expectations around the coexistence with the disease. Cartography, therefore, becomes a mapping of a phenomenon, considering its area of occurrence, of movement and of evolution. [45]

Thus, the cartographic apparatus maps the testimony of thinking, of acting, and of saying of the family members through their life story before and after the disease, what is extremely valiant in the decipherable activity of the strange and of the tragic, which are related to the dignity of the human person, in the course of its symbolic production. This professional's concern with each other in what is effectively lived is what promotes the ethical humanist process.

Subsequently, the social framework of collective production come cast off the concern with social exclusion caused by the pain and the psychic suffering peculiar to the disease. In this sense, it is necessary to establish a reciprocal contact with the contents of other institutions, in order to establish a true transdisciplinarity in transubjective field.

This collective production is precisely the cartography production of the family members' narratives, While the interlock between such production 
and other institutions will enable the interpretation of depression plasticity discourse, expressed in the rhetoric of enchantment perpetrated by the families in the cultural territory that round them.

By the analysis of those same narratives, the application of a methodological procedure of intervention appear us as safeguard of what is excessively human, because of that, it is possible to set a standardized model of confront against the disease, focused in what the family member to think, to say and unsay in its discourse, by revealing the feelings of pain and psychic suffering emanated from the depressive phenomenon.

However, the method to be applied must enhance and boost professional interpretation, offering compensation to the families, by filling the gaps of the disease in its daily translation. It must also be established in languages and a leveling of the terminologies, according to the cultural structure of the family members. It is clear that this is not an exercise in professional framework in the family members' whole life, but it is, above all, an approximation of values, ideas and enunciative cognitions that aimed at politicizing the disease as the prospects of voice and ears.

Thus, the recognition of the specific enunciation of the family members' culture in order $t$ to better understanding of the particularities of the disease, come to corroborate with the proposal of approximate the professional anonymous rhetoric with the poetic conducted by the disease desirous of narratives, which delineates a differential profile of old professional prospects of following the discourse in detriment of diagnosis. Lima [35] helps us to develop the idea of listening to the subaltern voices and of recognizing in them, their potential of social critic. To put it another way, through a dialogue calculated between the vertiginous analogy and the disenchantment antiphrasis.

That recognition should be based on the understanding and comprehension of the words related to the disease, originated from the popular culture, in the specific terminology of the social body, through a leveling work of the pathology relations with the problems of exclusion and lack of listening.

In a more including way, the introduction of public health policies can provide the rethink of the attendances, of the intervention, and of the treatment of the disease in the Center (CAPSi). The primary purpose of these policies is the unique opportunity to restructure the professional body in detriment of the needs identified in the course of childhood depression.

Thus, this policy proposal should emerge with substrate on the information collected, mapped and analyzed for purposes of fidelity with what requires the family member in its trajectory of contact with the professional. Continuous act, the clinical opinion of that professional must function as interlace in the final product to be pragmatically applied by these policies in the social sphere.

At the end, partnerships must be sealed with other institutions, in order to expand treatment and disease intervention, specifically by targeting the patient the direction of his depressive profile, from the clinical wisdom. This attitude aims to sanitize the disability issues in dealing with the disease, notably with the supply of institution failures in a new alliance with another, promoting an Alliance based on a look that focuses the hybridity of the belonging scriptures of the circularized knowledge of an institution to another, in what is believed to be a polyphonic dialogue. [43]

Projects, partnerships and proposals of non-governmental organizations also suggest backing in this process, because they demand social and political incision to the community, and by the support given by the society to these institutions, what can collaborate heavily in the socialization process of childhood depression.

As we have seen, what circularize the body with those suggestions it is the practice of offering the human to the human, with emphasis on the symbolic translation produced by the family members' poetics of social life, when valorize its life story on the disease, because of its problems and accomplis- 
hments in the amalgamate of pain and psychic suffering. Anyway, what we want here is to humanize the medical act to level the relationship in a manner that is sensitive and rational truth embedded in the interpretative family narratives.

It is thus, of thinking the depressive child with a reflected to the knowledge and practices of the truths of the discourses said "humans", to trigger other cognitive poles to meet and to live, to plan and make it happen ways of thinking and living the human condition. And, if it is not possible to take away for the full trappings of reductive thinking, let's assume the paradox of human knowledge always uncertain, partial, and unfinished. Maybe the science undertakes more with the "here" and the "now" of the human condition, that is, assuming itself as a reading of the partial world -a half-truth. It is an important step to feed the dialogue with other half-truths contained in the constellations of non-scientific knowledge. [43]In this meaning, the family demarcates differences and impossibilities, by requiring understanding and explanation to the dramas lived, particularly when attempts cease. Following this line of reasoning, Ingeborg Bachmann [46] retracts the universe of particular meanings involved in evils and/or misfortunes established by disease:

Among the trees a can't see trees

The branches don't have leaves to hold them in the wind.

The fruits are sweet, but without love

They don't satisfy the hunger.

And now, what is going to happen?

The woods flee before my eyes,

The birds close their beaks in my ears,

No lawn becomes my bed.

The time left me satiated

But I desire for it

And now, what is going to happen?

In the mountains, the fire will burn in the night Shall I set out, draw closer to them all again?

There's no longer a way I can see a way.

\section{References}

1. Foucault M. Un parcours philosophique. Paris: Gallimard, 1984.

2. Dreyfus H, Rabinow P. Michel Foucault, un parcous philosophique. Paris: Gallimard, 1984.

3. Foucault M. L'Ordre du discours. Leçon inaugurale ao Collège de France. Tradução de Edmundo Cordeiro e Antônio Bento. 1970 Dez [citado em 20 de outubro de 2016]: [36 páginas] disponível em: http://www.geocities.com/filosofiasf/discurso.htm.

4. Coser O. Depressão: clínica, crítica e ética. $20^{a}$ ed. Rio de Janeiro: Editora Fiocruz, 2003.

5. Morin E. O método I: a natureza da natureza. Europa-América: Mirasutra, 1987

6. Foucault M. O que um autor? Lisboa: Passagens/ Vega, 2002.

7. Figueiredo LCM. Escutar, recordar, dizer: encontros heideggerianos com a clínica psicanalítica. São Paulo: Escuta/ Educ, 1994.

8. Jamison KR. Uma mente inquieta: memórias de loucura e instabilidade de humor. São Paulo: Martins Fontes, 1996.

9. Ricouer P. Interpretação e ideologias. Rio de Janeiro: Francisco Alves, 1977.

10. Geertz C. A interpretação das culturas. Rio de Janeiro: Jorge Zahar Editores, 1978.

11. Solomon A. Demônio do meio-dia: uma anatomia da depressão. Rio de Janeiro: Objetiva, 2002

12. Modalização. In: Dicionário Aurélio. Versão 3.0. (CD-ROM), 1999.

13. Fédida P. Dos benefício da depressão: elogio da psicoterapia. $1^{\text {a }}$ ed. São Paulo: Escuta, 2002.

14. Jamison KR. Quando a noite cai: entendendo o suicídio. Rio de Janeiro: Gryphos, 2002.

15. Dias ML. Suicídio: testemunhos de adeus. São Paulo: Editora Brasiliense, 1997.

16. Abraham K. A shot study of the development of the libido viewed in the light of mental disorders. In. Selected papers on psychoanalysis. New York: Basic Book, 1927.

17. Wolkind S, Rutter M. Separation, loss and family relantionship. In. Rutter, M., Hersou, L. Child and adolescent psychiatry. Boston: Blackwell Scientific Publications, 1990.

18. Calderado RSS, Carvalho CV. depressão na infância: um estudo exploratório. Psicologia em Estudo 2005; 10(2):p.181-189.

19. Rodrigues MJSF. O diagnóstico da depressão. Psicologia USP 2000; 11(1):155-187.

20. Nakamura E, Santos JR. Depressão infantil: abordagem antropológica. Revista de Saúde Pública 2007; 41(10):p.53-60.

21. Bourdieu P. Poder simbólico. Lisboa: Difel, 1989.

22. Cortesão L, Stoer SR. Cartografando a transnacionalização do campo educativo: o caso português. In: Santos BS.(Org.). A globalização e as ciências sociais. $2^{\text {a }}$ ed. São Paulo: Cortez, 2002. p. 382. 
23. Jovchelovitch S, Bauer MW. Entrevista narrativa. In: Bauer MW, Gaskell G. Pesquisa qualitativa com texto, imagem e som: um manual prático. Petrópolis, RJ: Vozes, 2002. p. 91.

24. Bernstein B. The structuring of pedagogic discourse. Londres: Routledge, 1990.

25. Spencer J. The usefulness of qualitative methods in rehabilitation: issues of meaning of context and of change. Arch Phys Med Rehabil 1993; 74:119-126.

26. Barthes R. The semiotic challenge. Oxford: Basil Blackwell, 1993.

27. Bruner J. Acts of meaning. Cambridge: Harvard University Press, 1990.

28. Schutze F. Die technik des narrativen interviews in interaktionsfeldstudien - dargestelli an Einem projekt zur erforschung von kommunalen machtstrukturen. Manuscript of Bielefeld, Departament of sociology 1977. [in press]

29. Schutze F. Narrative repraesentation kollektiver schicksalsbetroffenheit. In: Laemmert E. Erzaehlforschung. Stuttgart: J.B. Mentzler, 1983. p. 568-90.

30. Pauliston RG. Mapping comparative education after postmodernity. In: Comparative Education Review: Compare 1999. p. 117-152.

31. Santos BS. Uma cartografia simbólica das representações sociais. Revista Crítica de Ciências Sociais 1988; 24:139-172.

32. Abell P. The syntax of social life: the theory and method of comparative narratives. Oxford: Oxford University Press, 1987.

33. Abell P. Some aspects of narrative method. J Math Sociol 1993; 18:93-134

34. Santos BS. Toward a new common sense: law, science and politics in the paradigmatic transition. New York: Routledge, 1995

35. Lima NC. Narrativas orais: uma poética da vida social. Brasília: Editora da Universidade de Brasília, 2003.

36. Foucault M. L'Archéologie du savoir. Paris: Gallimard, 1969.

37. Foucault M. L'Ordre du discours. Paris: Gallimard, 1971.

38. Riessman CK. Strategic uses of narrative in nursing research. J Adv Nurs 1990; 32(3):696-703.
39. Foucault M. A arqueologia do saber. Rio de Janeiro: Forense, 1986.

40. Foucault M. Microfísica do poder. Rio de Janeiro: Graal, 1992.

41. Barre L. The cultural basis of emotions and gestures. J Pers 1947; (16):49-68

42. Helman GG. Cultura, saúde e doença. Porto Alegre: Artmed, 2003.

43. Almeida MCX. As artes da nova ciência. In: Almeida MCX, Knobb M, Almeida AM. Polifônicas ideias: por uma ciência aberta. Porto Alegre: Sulina, 2003. p. 31.

44. Rodrigues ML. Os bons medos. In: Almeida MC, Knobb M, Almeida AM. Polifônicas ideias: por uma ciência aberta. Porto Alegre: Sulina, 2003. p. 169.

45. Cartografia. In: Novo Dicionário da Língua Portuguesa. $2^{a}$ ed. Rio de Janeiro: Nova Fronteira, 1986.

46. Bachmann, I. Samtliche gedichte [poemas completos]. Piper. Munique/Zurique, 2001.
Publish in International Archives of Medicine

International Archives of Medicine is an open access journal publishing articles encompassing all aspects of medical science and clinical practice. IAM is considered a megajournal with independent sections on all areas of medicine. IAM is a really international journal with authors and board members from all around the world. The journal is widely indexed and classified Q2 in category Medicine. 